\title{
IMPREGNATING MAGNETIC COMPONENTS WITH MDA FREE EPOXY
}

\author{
Robert O. Sanchez \\ Sandia National Laboratories \\ Albuquerque, New Mexico \\ Linda Domeier \\ Sandia National Laboratories \\ Livermore, California \\ Shelton Gunewardena \\ Mil-Spec Magnetics, Inc. \\ Walnut, California.
}

\begin{abstract}
This paper describes the use of "Formula 456" an aliphatic amine cured epoxy for impregnating coils. Methylene dianiline (MDA) has been used for more than 20 years as the curing agent for various epoxy formulations throughout the Department of Energy. Sandia National Laboratories began the process of replacing MDA with other formulations because of regulations imposed by OSHA on the use of MDA.
\end{abstract}

\section{INTRODUCTION}

The magnetic components required to support the various Department of Energy (DOE) and Department of Defense programs include transformers, solenoid coils, and inductors. A rugged package is essential because of some military type applications where high voltage, size and severe enviroriments are major considerations. For more than 20 years Sandia National Laboratories (SNL) has used a formula defined in SNL process specification 9927020 for encapsulating/impregnating these type of coils. The formula consists of an epoxy resin (Epon 828), a hardener methylene dianiline (MDA), a filler (normally mica), and some color paste. OSHA has regulated MDA because it is a suspect carcinogen. Formulation development for MDA-free epoxies has targeted not only the replacement of MDA, but also the improvement of other formulation properties and processability. Typically the elimination of OSHA regulated materials provides a rare opportunity to qualify new formulations in a range of demanding applications. It is important to take full advantage of that opportunity and the costly materials qualification effort associated with it.
SNL and the DOE production agencies have evaluated a number of MDA-free epoxy encapsulants which relied on either anhydride or other aromatic amine curing agents. The use of aliphatic amine curing agents was evaluated only more recently and has resulted in the definition of two promising alternative resins. Both rely on the same Bis A epoxies previously used with MDA, and both use the same replacement curing agents; a blend of Jeffamine D-230 (a flexible polyether diamine) and Ancamine 2049 (a cycloaliphatic diamine). Formula 456 is a rubber modified formulation which also includes a Dow Bis A epoxy containing $40 \%$ by weight of a phase-separated rubber modifier (Dow XU-71790). Formula 459 contains only a unmodified Bis A epoxy and adds a silicone based de-gassing aid. Both formulations are readily processed at temperature below those required for the MDA cured formulations. They possess lower viscosities and also degas very effectively. Electrical and mechanical properties are typically comparable to or better than those of similar MDA cured materials.

\section{THE PROCESS}

A power transformer identified as 378012 , and a pulse transformer identified as 378128 were selected as the baseline design components used to evaluate this MDA free encapsulant. MIL-SPEC MAGNETICS, INC. undertook the task of evaluating Formula 456 on the two different transformer designs. Two lots of fifty parts each were used during the evaluation. SNL specification SS396751 was followed during encapsulation. Part number 378012 was of special interest because of the intricate winding and insulation interleaving pattern of its design. The challenge was to ensure that the encapsulant totally reaches the spaces between each layer of Kraft paper and between the winding wire spaces. 


\section{DISCLAIMER}

Portions of this document may be illegible in electronic image products. Images are produced from the best available original document. 


\section{POWER TRANSFORMER APPLICATION}

The transformer is used in a flyback converter to charge a capacitor to 4.2KV (see Figure 1).

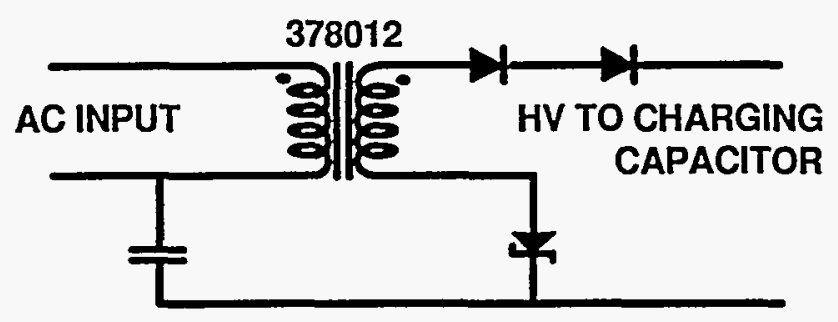

Figure 1

\section{POWER TRANSFORMER DESIGN}

The design for the 378012 power transformer is described to provide an understanding of the difficulty of impregnating this type of coil.

DESIGN AND PROCESSES: The Primary winding consist of 26 turns of 29 gage, polyester-insulated copper magnet wire closely wound and centered within the flanges of a nylon bobbin. The secondary winding consists of 1114 turns of 40 gage, heavy polyesterinsulated copper magnet wire closely wound and centered within the bobbin flanges. The primary is placed in a single layer and separated from the secondary using Kraft paper insulation (KP). The secondary is divided into 21 layers, with KPI separating each layer. Several layers of KPI are placed over the last layer. The finish of the secondary winding is internally spliced to a Tefloninsulated, flexible-stranded high voltage lead wire.

$$
\text { ... }
$$

CORE / COIL SUBASSEMBLY: The coil is assembled into a matched set of 2616 ferrite pot. The core halves are bonded to each other, using a thixotropic epoxy adhesive, and to a pre-molded diallyl phthalate (DAP) contact assembly using the sealing compound polysulfide. The start and finish of the primary, and the start of the secondary are stripped, cleaned, and soldered to their appropriate pins on the DAP contact assembly. The core halves are painted with a Phenolic micro balloon filled polysulfide (Ref. 1) for the purpose of reducing stresses caused by differences in coefficient of thermal expansion between the ferrite core and the epoxy encapsulating system (Ref. 2). The center cavity of the core is also filled with the polysulfide resin to exclude epoxy from the cavity. The assembly is vacuum baked and plasma cleaned prior to the encapsulation process to promote adhesion of the epoxy to the DAP contact assembly.

\section{ENCAPSULATION}

The following covers the procedure for the encapsulation and impregnation of magnetic devices using Formula 456.

\section{COIL DRYING:}

a. The coils shall be dried in a vacuum oven at a temperature of $110 \pm 12^{\circ} \mathrm{C}$. They shall be held at this temperature at a maximum pressure of $25 \mathrm{~mm} \mathrm{Hg}$ absolute for a minimum of 4 hours, after which the vacuum shall be broken with dry nitrogen.

b. The units shall then be cooled to and stabilized at 54 $\pm 6^{\circ} \mathrm{C}$ and maintained at this temperature until ready for encapsulation. They shall be stabilized at this temperature either under dry nitrogen atmosphere, or in a vacuum oven at a maximum pressure of $25 \mathrm{~mm} \mathrm{Hg}$ absolute after which the vacuum shall be broken with dry nitrogen.

DRYING OF FILLER: The mica filler shall be dried by placing the material in a shallow pan, not over two inches in depth, and baked for four hours minimum in a forced convection oven at a temperature of $107 \pm 6^{\circ} \mathrm{C}$.

FORMULATION: Unless otherwise noted, tolerance on weights of material shall be $\pm 1 \%$.

\begin{tabular}{|c|c|}
\hline Material & Parts By Weight \\
\hline Epoxy Resin & 75 \\
\hline Mica Filler & 65 \\
\hline Curing Agent & 25 \\
\hline Color Paste & $1.00+/ .25$ \\
\hline
\end{tabular}

MIXING: The preferred batch size is 166 grams combined weight. The maximum recommended batch size is 700 grams. Materials must be homogenous.

a. Combine the epoxy resin, filler and color paste. Mix until material is uniform throughout.

b. Heat or cool the mixture to $54 \pm 3^{\circ} \mathrm{C}$ and add the curing agent which shall be at room temperature (18 to $29^{\circ} \mathrm{C}$ ). Mix until material is uniform throughout.

c. Immediately after mixing, evacuate at a pressure of 0.5 to $3.0 \mathrm{~mm} \mathrm{Hg}$ absolute and a temperature of $74 \pm 6^{\circ} \mathrm{C}$ for a minimum of 1 minute and a maximum of 3 minutes 
after the initial foam rise collapses. If time to collapse is not visible then 2 minutes minimum and 4 minutes maximum.

\section{POURING UNDER VACUUM:}

a. Place the preheated molds with components in a vacuum chamber and evacuate at a pressure of 0.5 to $3 \mathrm{~mm} \mathrm{Hg}$ absolute.

b. The deaerated mixture temperature should be at $45^{\circ} \mathrm{C}$ to $60^{\circ} \mathrm{C}$ and should immediately be poured into the mold under vacuum. The pressure shall be decreased to 0.5 to $3.0 \mathrm{~mm} \mathrm{Hg}$ for a minimum of three minutes after pouring the last unit. Break vacuum slowly, 3 minutes minimum to avoid voids.

CURE: The compound shall be cured in a pressure chamber at 80 PSI minimum for 4 hours $+1-1$ hour @ 25 $+/-5^{\circ} \mathrm{C}$, plus 6 hours $+/-1$ hour @ $60+/-3^{\circ} \mathrm{C}$, plus 12 hours +/-1 hour @ $93+/-3^{\circ} \mathrm{C}$. At the end of cure let parts cool in chamber for 30 minutes minimum.

\section{MACHINING TO DIMENSION AND MARKING:}

Each transformer is machined to the proper height following removal from the RTV mold. After machining, the part is identified and serialized with epoxy marking.

THERMAL CYCLE AND TEST: Each transformer is subjected to 5 four-hour thermal cycles prior to inspection and test which helps in relieving internal stresses. The temperature extremes for each cycle are $-60^{\circ} \mathrm{C}$ to $+93^{\circ} \mathrm{C}$, and each cycle requires one hour exposure at each of these temperatures. Each transformer is visually inspected then electrically tested. The electrical tests consist of: DC resistance, inductance, capacitance, turns ratio, polarity, insulation resistance, and induced voltage (corona test).

ENVIRONMENTAL TEST: As a minimum, this transformer design is subjected to the following environments: $3500 \mathrm{G}$ mechanical shock; sinusoidal vibration - frequency range $(\mathrm{Hz})$ 10-2000-10; random vibration - complex power spectral density from $5 \mathrm{~Hz}$ to $2000 \mathrm{~Hz}$ at $.001 \mathrm{G}^{2} / \mathrm{Hz}$ to $.4 \mathrm{G}^{2} / \mathrm{Hz}$; steady state acceleration $100 \mathrm{G}$ for 10 seconds; temperature shock - 3 cycles $-55^{\circ} \mathrm{C}$ to $+100^{\circ} \mathrm{C}$; and temperature cycle 110 cycles $-60^{\circ} \mathrm{C}$ to $+93^{\circ} \mathrm{C}$. The design is tested to these environments during qualification.

The mica-filled epoxy resin system must provide a rugged system that is capable of surviving high levels of shock and vibration, while having stable characteristics over a 25-year period.

POLYSULFIDE COATING: The process of painting the ferrite core with a phenolic micro-balloon filled polysulfide resin was implemented to reduce the stresses that are caused by the difference in coefficient of thermal expansion between the ferrite core and the epoxy resin (Ref 1). The polysulfide system was selected for this application because it adheres well to the ferrite core material, and the epoxy resin bonds well to the cured polysulfide. The Phenolic micro-balloons, 3.3\% fill by weight, provide a crushable medium to relieve compressive stresses.

\section{RESULTS}

The process specified in S\$396751 (and specified above) was followed closely. No coloring paste was used. Initially the batch size of the combined formula was 165 grams. Subsequent batches were reduced to 82.5 grams when it was observed that the formula tended to thicken during the vacuum encapsulation process. In order to speed up the elapsed time between encapsulations, a motorized carousel was used inside the vacuum chamber to index each part directly under the nozzle feeding the encapsulant. The following charts list the material characteristics for Formula 456. Chart 1 lists unfilled material, glass micro balloon filler, alumina filler, and mica filler. Chart 2 lists Formula 456, Formula 459, and MDA material characteristic comparisons. 
FORMULA 456 DATA BASE

\section{PROPERTY}

$\mathrm{Tg},{ }^{\circ} \mathrm{C}$ (DMA at SNL/CA)

(DSC at Pinellas)

Thermal cycle cracks (after 10 cycles of nut \& bolt specimen)

Fracture toughness

CTE

(ppm from -50 to $22 / 22$ to $74^{\circ} \mathrm{C}$ )

Density

Dielectric strength, V/mil

Volume Resistivity, ohm-cm

Dielectric Constant at $100 \mathrm{~Hz}$ at $1 \mathrm{KHz}$ at $1 \mathrm{MHz}$

Dissipation Factor at $100 \mathrm{~Hz}$ at $1 \mathrm{KHz}$ at $1 \mathrm{MHZ}$

Pulse Dielectric at $-54^{\circ} \mathrm{C}$ Strength, at $25^{\circ} \mathrm{C}$ $\mathrm{KV} / \mathrm{mil} / \mathrm{Bkdn} \quad$ at $71^{\circ} \mathrm{C}$

Tensile strength, psi maximum at break

Tensile modulus, Ksi

Elongation

$$
\text { at max load }
$$
at break

Butt tensile adhesive strength: ceramic substrate - initial after $100 \mathrm{TCs}$ Al 2024 substrate - initial after $100 \mathrm{TCs}$ Al 7075 substrate - initial after $100 \mathrm{TCs}$

Lap shear adhesive strength, Al/Al (Al 2024) unfilled

GMB, phr

$30 \quad 35$

Mlumina, phr

250

300

mica, phr

60

70

95

110

103104

103100

111106

0

$0 \quad 0$

$0 \quad 0$

0

1.74

$0.97 \quad 0.90$

$2.66 \quad 2.78$

$1.86 \quad 1.90$

$69 / 80$

$39 / 4437 / 42$

$29 / 37 \quad 25 / 33$

1.12

$0.72 \quad 0.70$

2.27

631

$419 \quad 443$

$549 \quad 567$

$593 \quad 604$

1.67

$7.67 \quad 3.68$

$1.48 \quad 3.88$

$2.16 \quad 0.97$

3.96

$\begin{array}{ll}2.79 & 2.72\end{array}$

\begin{tabular}{ll}
$5.63 \quad 5.83$ \\
\hline
\end{tabular}

$\begin{array}{ll}5.55 & 5.77\end{array}$

$5.32 \quad 5.55$

$\begin{array}{ll}6.39 & 5.99\end{array}$

$2.70 \quad 2.60$

$2.60 \quad 2.48$

3.58

$\begin{array}{ll}.050 & .057\end{array}$

$.021 \quad .020$

$.022 \quad .019$

$.019 \quad .018$

$.021 \quad .018$

$\begin{array}{ll}4.58 & 4.27\end{array}$

4.48 na

$4.01 \quad 3.86$

$5.46 \quad 5.49$

$4.06 \quad 4.15$

11.69

8.92

$\begin{array}{ll}2.69 & 2.38\end{array}$

2.36 na

$2.25 \quad 1.83$

5128

10,100

10,100

8550

360

424

2200

$9.6 \%$

$1.3 \%$

$1.1 \%$

1513

995
751

$1.5 \%$

$.051 \quad .052$

$.059 \quad .062$

$.041 \quad .043$

4.89

$3.46 \quad 3.96$

$3.98 \quad 4.06$

7235

-- 


\section{FORMULATION 456, 459 AND MDA COMPARISON}

Composition:

$\underline{\text { Rubber modifier content }}$

Appearance, unfilled

Tg(DMA, storage mod.) (DSC)

NH/epoxy stoichiometry

CTE $\left(-50^{\circ}-22^{\circ} 22^{\circ}-50^{\circ} \mathrm{C}\right)$ unfilled

with 250-350 phr alumina

Thermal cycle (10) cracks unfilled with $300 \mathrm{phr}$ alumina

Tensile properties unfilled:

strength, maximum atbreak

modulus

elongation, at max load at break

Tensile properties with 250-350 phr alumina: strength, maximum at break

modulus

elongation, at max load at break

$60^{\circ} \mathrm{C}$ viscosity data initial viscosity time to double time to $600 \mathrm{cps}$
MDA

Formulation toughened

20 Shell $Z$

100 Epon 828-

CTBN

(X8 at 10 wt. \%)
MDA

Formulation

$$
\text { plain }
$$

\section{Formula 456}

Formula 459

20 Shell Z

12.5 Jeffamine

D-230

100 Epon 828

12.5 Ancamine 2049

50.0 Shell Epon

826

25.0 Dow

XU-71790

8.3 wt percent

none

yellow, cloudy

yellow, clear

$98^{\circ} \mathrm{C}$

10 wt percent

none

white, opaque

yellow, clear

$95^{\circ} \mathrm{C}$

$110^{\circ} \mathrm{C}$

1.11

1.00

1.16

1.01

\section{$22 / 28$}

(250 phr)

69/80 ppm

25/33 ppm

(300 phr)

$51 / 56 \mathrm{ppm}$

19/25

(360 phr)

0

5

0

0

6

0

8900 psi

11,490

10,380

$360 \mathrm{Ksi}$

$487 \mathrm{Ksi}$

$9.6 \%$

$5.0 \%$

$-$

$7.3 \%$

(250 phr)

10,700

-.

$2230 \mathrm{Ksi}$

$0.5 \%$

$-$
(300 phr Alox)

$10,100 \mathrm{psi}$

$10,100 \mathrm{psi}$ $2200 \mathrm{Ksi}$

$1.1 \%$

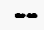

(300 phr Alox)

$10,840 \mathrm{psi}$

$10,840 \mathrm{psi}$

$2870 \mathrm{Ksi}$

$0.6 \%$

$0.6 \%$
$555 \mathrm{cps}$

$35 \mathrm{~min}$.

$6 \mathrm{~min}$.
$115 \mathrm{cps}$

$17 \mathrm{~min}$.

$36 \mathrm{~min}$.
$67 \mathrm{cps}$

$19 \mathrm{~min}$.

$42 \mathrm{~min}$. 


\section{CONCLUSION}

We consider and rate the Formula 456 encapsulant as an excellent method of encapsulating intricate parts similar to the $\mathrm{P} / \mathrm{N} 378012$. The fifty 378012 and the fifty 378128 parts were visually inspected and electrically tested. No voids were observed in any of the parts and no differences were noted in any of the electrical characteristics. The 378012 parts were machined to size on a lathe. The 378128 parts were machined to size on a milling machine. We did not have any delamination of the encapsulant from the contact assemblies.

\section{SUGGESTIONS BY MIL-SPEC MAGNETICS}

A two-part formula with the Mica incorporated into the epoxy resin would be desirable. We would prefer a longer pot-life of the mixed formula. This would result in more economical production.

\section{REFERENCES}

1.) R. O. Sanchez, "A Method for Reducing Encapsulation Stress to Ferrite Pot Cores", EMCW'94 Proceedings, 1994, pp 183-189.

2.) R. O. Sanchez, "A Method for Encapsulating High Voltage Power Transformers", CARTS '91 Proceedings, 1991, pp 42-47.

\section{ACKNOWLEDGMENTS}

This work was supported by the United States Department of Energy under contract DE-ACO494AL 85000.

\section{DISCLAIMER}

This report was prepared as an account of work sponsored by an agency of the United States Government. Neither the United States Government nor any agency thereof, nor any of their employees, makes any warranty, express or implied, or assumes any legal liability or responsibility for the accuracy, completeness, or usefulness of any information, apparatus, product, or process disclosed, or represents that its use would not infringe privately owned rights. Reference herein to any specific commercial product, process, or service by trade name, trademark, manufacturer, or otherwise does not necessarily constitute or imply its endorsement, recommendation, or favoring by the United States Government or any agency thereof. The views and opinions of authors expressed herein do not necessarily state or reflect those of the United States Government or any agency thereof. 